\title{
Zoneamento Bioclimático da Ovinocultura no Estado do Paraná
}

\section{Orlando Rus Barbosa1, Francisco de Assis Fonseca de Macedo', Roland Van de Groes², José Maurício Franco Guedes ${ }^{3}$}

\begin{abstract}
RESUMO - Utilizaram-se 45 fêmeas ovinas adultas (15 Hampshire Down [HD], 15 Texel [TE] e 15 Ile de France [IF]), para propor um zoneamento bioclimático da ovinocultura no Estado do Paraná. Mediram-se a temperatura retal (Tr), da epiderme (Te), do interior do velo (Tiv) e da superfície do velo (Tsv); a frequência respiratória (Fr); a temperatura do ar (Ta), pressão de vapor (e), velocidade do vento $(v)$ e carga térmica radiante (CTR). O Índice de Conforto Térmico utilizado foi ICT $=0,6678 \mathrm{Ta}+0,4969 e+0,5444 \mathrm{Tg}+0,1038 v$. A regressão do ICT sobre Tr mostrou efeito quadrático para as três raças. Para ICT=24,3, 27,3 e 20,6, os valores de Tr foram respectivamente: $39,10^{\circ} \mathrm{C}$ para a raça $\mathrm{HD}, 39,05^{\circ} \mathrm{C}$ para TE e $39,09^{\circ} \mathrm{C}$ para IF, atingindo 40,$40 ; 40,50 ;$ e $40,28^{\circ} \mathrm{C}$, respectivamente, para ICT=58. As três raças aumentaram sua $\mathrm{Tr}$ a partir de ICT=26, com a TE apresentando menor Tr até o valor ICT=46; neste ponto, as três raças foram semelhantes, tendo a TE apresentado maiores valores. Para ICT igual a 27,6; 29,7; e 27,0, os valores de Fr foram, respectivamente, 89,63; 77,08; e 78,77 resp./min., para as raças HD, TE e IF. A raça TE apresentou menor Fr (77,08 resp./min.), para ICT=29,7 e para ICT=48, valores semelhantes aos da IF (181,96 resp./min.); a partir deste índice, passou a ser maior que as demais raças, atingindo valores de 288,66 resp./min. no ICT=56, porém inferior à HD (289,01 resp./min.). Neste índice, a raça IF foi a que apresentou a menor Fr (275,72 resp./min.). Uma extensa faixa ao longo do litoral do Estado, entrando cerca de $200 \mathrm{~km}$ para o interior até os limites das cidades de Castro, Telêmaco Borba, Laranjeiras do Sul e Pato Branco, permite a criação das três raças, sem exigir grandes esforços de termorregulação.
\end{abstract}

Palavras-chave: frequência respiratória, ovinos, temperatura retal, zoneamento bioclimático

\section{Bioclimatical Zoning of Sheep Breeding in the State of Parana}

\begin{abstract}
Forty five adult ewes were used, 15 for each of the three breeds: Hampshire Down (HD), Texel (TE) and Ile de France (IF). These animals were measured for rectal temperature $(\mathrm{Rt})$, skin temperature $(\mathrm{St})$, fleece temperature $(\mathrm{Ft})$, temperature of the coat surface (Cst) and respiratory rate (Rr), Air temperature (At), air vapour pressure (Avp), wind speed (Ws), globe temperature (Gt) and radiant heat load $(\mathrm{Rhl})$ were also recorded. The Thermal Comfort Index equation was used: $\mathrm{TCI}=0.6678 \mathrm{Ta}+0.4969 \mathrm{e}+0.5444 \mathrm{Tg}+$ $0.1038 \mathrm{v}$. Regression of TCI on Rt showed quadratic effect for the three breeds. For a TCI $=24.3,27.3$ and 20.6, Rt values were: $39.10^{\circ} \mathrm{C}$, for $\mathrm{HD}, 39.05^{\circ} \mathrm{C}$ for $\mathrm{TE}$, and $39.09^{\circ} \mathrm{C}$; for IF sheeps and for TCI $=58$, these values were respectively $40.40^{\circ} \mathrm{C}, 40.50^{\circ} \mathrm{C}$ and $40.28^{\circ} \mathrm{C}$. All the animals presented increased Rt under theses index, with Texel showed the least Rt for TCI=46, but was the only group with higher Rt values for TCI>48. For TCI=27.6, 29.7 and 27.0, Fr values were respectively: $89.63 \mathrm{resp} . / \mathrm{min}$. for HD, $77.08 \mathrm{resp} . / \mathrm{min}$. for TE and $78.77 \mathrm{resp} . / \mathrm{min}$. for IF. TE presented smaller $\operatorname{Rr}(77.08 \mathrm{resp} . / \mathrm{min}$.), for TCI=29.7, and values similar to IF (179.63 resp./min.), under $\mathrm{TCI}=48$. After this level TE values were higher than those of the other breeds, reaching $288.66 \mathrm{resp} . / \mathrm{min}$. for TCI=56, but inferior that HD (289.01 resp./min.); IF, presented lower Rr (275.72 resp./min.). An extensive strip of land along the Parana State coast, heading inland $200 \mathrm{~km}$ up to the borders Castro, Telêmaco Borba, Laranjeiras do Sul and Pato Branco cities, allows the creation of the three breeds.
\end{abstract}

Key Words: bioclimatical zoning, rectal temperature, respiratory rate, sheep.

\section{Introdução}

O estabelecimento de um sistema de criação economicamente viável em determinada região requer a escolha de raças ou variedades que sejam perfeitamente adequadas às condições ambientais locais.

O essencial na produção ovina é desenvolver raças bem adaptadas às diferentes localidades para que possam expressar ao máximo o seu potencial genético (HAFEZ et al., 1956).
Dos animais domésticos, o ovino é um dos que apresentam mecanismos anatomofisiológicos mais propícios à sobrevivência em regiões de altas temperaturas, desde que a umidade do ar seja baixa. A lã deve ser encarada como um isolante térmico, com a função de proteger os animais dos efeitos da intensa radiação solar. As raças mais especializadas para produção de lã, denominadas raças de lã fina, são justamente as que melhor se adaptam às condições de altas temperaturas, considerando que seu velo fino e

\footnotetext{
1 Professores do Departamento de Zootecnia da UEM,Av.Colombo,5790,87020-900 -Maringá,PR.E.mail:orbarbosa@uem.br; fafmacedo@uem.br 2 Acadêmico do curso de Zootecnia da UEM - Bolsista PIBIC/CNPq.

3 Analista de Sistema, IPMET, UNESP, Bauru, SP.
} 


\section{BARBOSA et al.}

denso representa uma barreira à transmissão de calor para a superfície corporal do animal (SIQUEIRA, 1990).

Entre as espécies animais de interesse econômico exploradas no Estado do Paraná, a ovina é a que tem apresentado maior crescimento nos últimos 10 anos, com taxa média anual superior a $6 \%$. Até o final da década de 70, a produção ovina no Estado era voltada quase que exclusivamente para a produção de lã, utilizando-se animais puros ou mestiços com tal aptidão, especialmente as raças Corriedale e Ideal e seus mestiços. Por meio da importação e distribuição de raças produtoras de carne, principalmente Suffolk, Hampshire Down, Texel e Ile de France, o criador de ovinos passou a se especializar na produção de carne, utilizando-se os cruzamentos de raças de corte com o rebanho original de produção de lã (BONA FILHO et al., 1991).

Os vários tipos de ovinos criados neste Estado devem encontrar, em alguma região ou sub-região de sua área, conforto fisiológico que provavelmente dispensará, instalações e manejo adicionais para um rendimento satisfatório.

A adaptabilidade a ambientes tropicais e subtropicais é um fator muito importante na criação e na produção ovina. Diferentes raças têm diferentes características que se refletem nas respostas dos animais, em particular no padrão de comportamento no pastejo, na busca de sombra, descansando e ruminando (SHAFIE e SHARAFELDIN, 1965). O estresse por calor tem sido reconhecido como importante limitação para o ovino, influenciando na produção de lã. A perspectiva a curto ou médio prazos de se criarem alterações ambientais adequadas para diminuir o impacto das condições existentes não parece ser economicamente viável. A alternativa seria selecionar animais capazes de produzir satisfatoriamente, apesar dos rigores do ambiente, sendo esta a solução mais prática para o problema (HOPKINS et al., 1978).

MONTY et al. (1991) destacaram a necessidade do conhecimento da tolerância e da capacidade de adaptação das diversas raças como forma de embasamento técnico à exploração ovina, bem como das propostas de introdução de raças em uma nova região ou mesmo o norteamento de programa de cruzamento, visando à obtenção de tipos ou raças mais adequadas a uma condição específica de ambiente.

BARBOSA et al. (1995), trabalhando com as raças ovinas, Corriedale, Suffolk e Ideal nos Estados de São Paulo e Paraná, verificaram que sua distribuição nas diferentes regiões está associada principalmente à temperatura e à umidade do ar, embora outros elementos climáticos como a radiação solar, o vento, a latitude e altitude tenham sua contribuição. Constataram que regiões secas e quentes eram propicias às raças especializadas para lã (Ideal); regiões úmidas e frias, mais específicas para raças de carne (Suffolk); e regiões intermediárias, propícias para raças mistas (Corriedale).

Entre os fatores ambientais mais importantes e condicionantes estão os elementos climáticos. Assim, o zoneamento bioclimático tornar-se-ia importante recurso zootécnico para aumentar a eficiência da produção, por meio da distribuição adequada dos animais nas regiões de clima especificado.

No Estado do Paraná, onde a ovinocultura não tinha tradição e se encontra atualmente em expansão, é fundamental a execução de uma série de estudos envolvendo as diversas raças disponíveis, de modo a permitir evolução adequada e ordenada dessa atividade.

O objetivo do presente trabalho foi a proposição de um zoneamento bioclimático da ovinocultura no Estado do Paraná, visando à distribuição mais racional de algumas raças ovinas, baseando-se em critérios de conforto térmico.

\section{Material e Métodos}

Foram utilizadas 45 fêmeas adultas (15 Hampshire Down, 15 Ile de France e 15 Texel) com idade de 3,5 anos, ao sol e à sombra, no município de Cidade

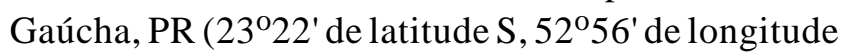
$\mathrm{W}$ e $550 \mathrm{~m}$ de altitude). Os dados foram coletados no período de dezembro de 1996 a fevereiro de 1997 , perfazendo um total de 2700 observações.

As observações foram efetuadas, em diferentes combinações de variáveis ambientais e apenas em dias de sol, às $8 \mathrm{~h} 30$ e $13 \mathrm{~h}$, para cinco características: temperatura retal ( $\mathrm{Tr})$, temperatura da epiderme (Te), temperatura do interior do velo (Tiv), temperatura da superfície do velo (Tsv) e frequiência respiratória (Fr), sendo a Te, Tiv e Tsv obtidas entre as linhas dos processos (apófises) transversos e processos espinhosos ( região dos rins) e sempre do lado esquerdo do animal. Todas as temperaturas foram obtidas com termômetro digital. A temperatura da superfície do velo foi obtida utilizando-se um disco de isopor para proteger do calor radiante a ponta do termômetro em contato com a lã, medindo, assim, apenas a temperatura da superfície do velo.

A Fr foi medida pela contagem dos movimentos dos flancos, com o auxílio de um cronômetro, durante 
15 segundos, multiplicando-se o resultado por quatro.

As seguintes variáveis ambientais foram consideradas: temperatura do ar (Ta), pressão de vapor (e), temperatura do globo negro (Tgn) e velocidade do vento (v). A Ta e $a$ e foram obtidas por meio de um psicrômetro não ventilado e a velocidade do vento, por meio de um catatermômetro, o qual é muito sensível para pequenos deslocamentos de ar, conforme SILVA e BRASIL (1986). Para obtenção da Tgn, foi utilizado um globo de Vernon de 0,15 m de diâmetro, colocado $0,5 \mathrm{~m}$ acima do solo no mesmo local dos animais. A temperatura do globo foi medida também para estimar a carga térmica radiante (CTR), conforme SILVA (1989).

Para traçar as isolinhas da Ta, Umidade relativa (Ur), v e Insolação (n), foram utilizados dados climáticos médios de 14 anos, abrangendo os anos de 1983 a 1996, num total de 32 estações meteorológicas no Estado do Paraná.

Os valores mensais da Ta, U, v e n, obtidos para cada estação meteorológica, foram correlacionados com suas respectivas latitudes, longitudes e altitudes, para se obterem as equações de regressão múltipla. $\mathrm{O}$ método utilizado para estabelecer essas equações foi o dos quadrados mínimos (UFV, 1997), segundo a expressão geral:

$$
\mathrm{Yi}=\mathrm{a}+\mathrm{bX} 1+\mathrm{cX} 2+\mathrm{dX} 3
$$

em que Yi refere-se a elementos climáticos (temperatura e umidade relativa do ar, vento e insolação); $\mathrm{X} 1$, latitude, em graus; X2, longitude, em graus; $\mathrm{X} 3$, altitude, em metros.

Estas equações possibilitaram o cálculo dos elementos climáticos em pontos de grade (latitude, longitude e altitude). Estes cálculos foram realizados para intervalos de meio grau de latitude e de longitude, cobrindo a área total do Estado, sendo traçadas as isolinhas com esta disposição em grade das variáveis climáticas.

O conjunto de médias meteorológicas caracterizando cada localidade, em todos os meses do ano, foi multiplicado pelo índice de conforto térmico (ICT), conforme BARBOSA et al. (1995), ou seja, $\mathrm{ICT}=0,6678 \mathrm{Ta}+0,4969 \mathrm{e}+0,5444 \mathrm{Tg}+0,1038 \mathrm{v}$, construindo assim as isolinhas de conforto térmico.

Os mapas estaduais com as isolinhas foram desenvolvidos no Instituto de Pesquisas Meteorológicas (IPEMET) de Bauru, SP, pelo analisador gráfico NCAR (National Center for Atmospheric Research).

Das isolinhas obtidas para as variáveis acima mencionadas foram selecionados os meses de janeiro
(Figura 1), maio (Figura 2), julho (Figura 3) e outubro (Figura 4), por melhor representarem as estações do ano, com base nos valores de umidade do ar e do Índice de Conforto Térmico.

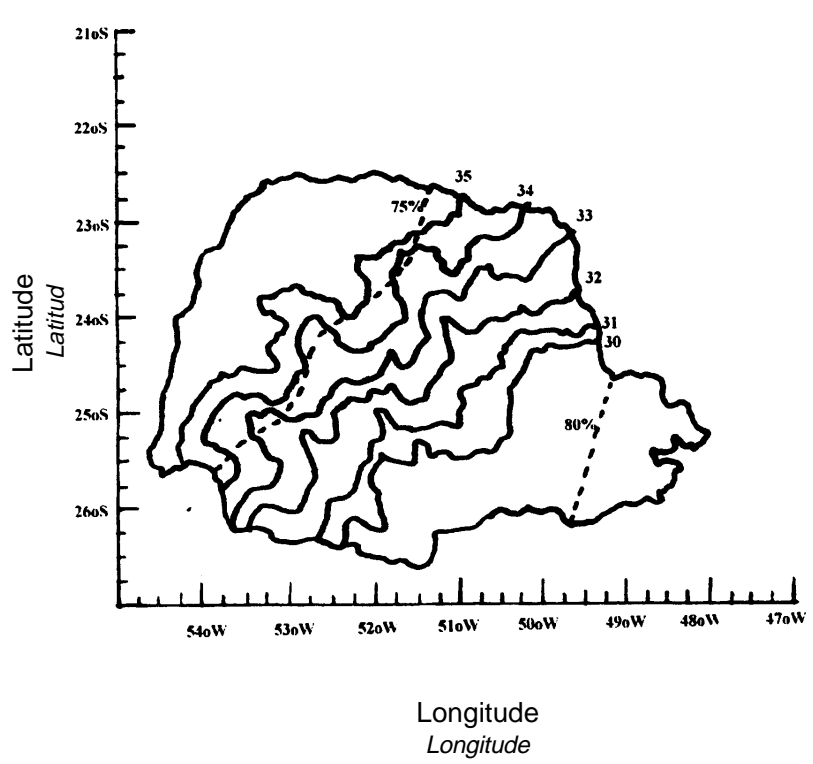

Figura 1 - Isolinhas de Conforto Térmico (linhas contínuas) e de Umidade Relativa do ar (\%) (linhas pontilhadas), no mês de janeiro, no Estado do Paraná.

Figura 1 - Isolines of Thermal Comfort (continuous lines) and Air Relative Humidity (\%) (stripped lines) for the month of January, in the State of Parana.

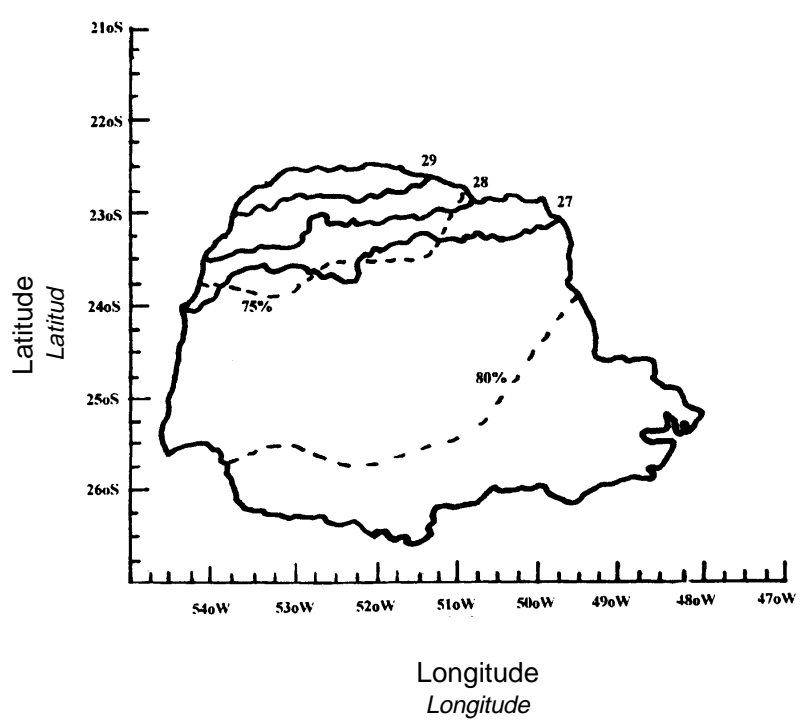

Figura 2 - Isolinhas de Conforto Térmico (linhas contínuas) e de Umidade Relativa do ar (\%) (linhas pontilhadas), no mês de maio, no Estado do Paraná.

Figura 2 - Isolines of Thermal Comfort (continuous lines) and Air Relative Humidity (\%) (stripped lines) for the month of May, in the State of Parana. 


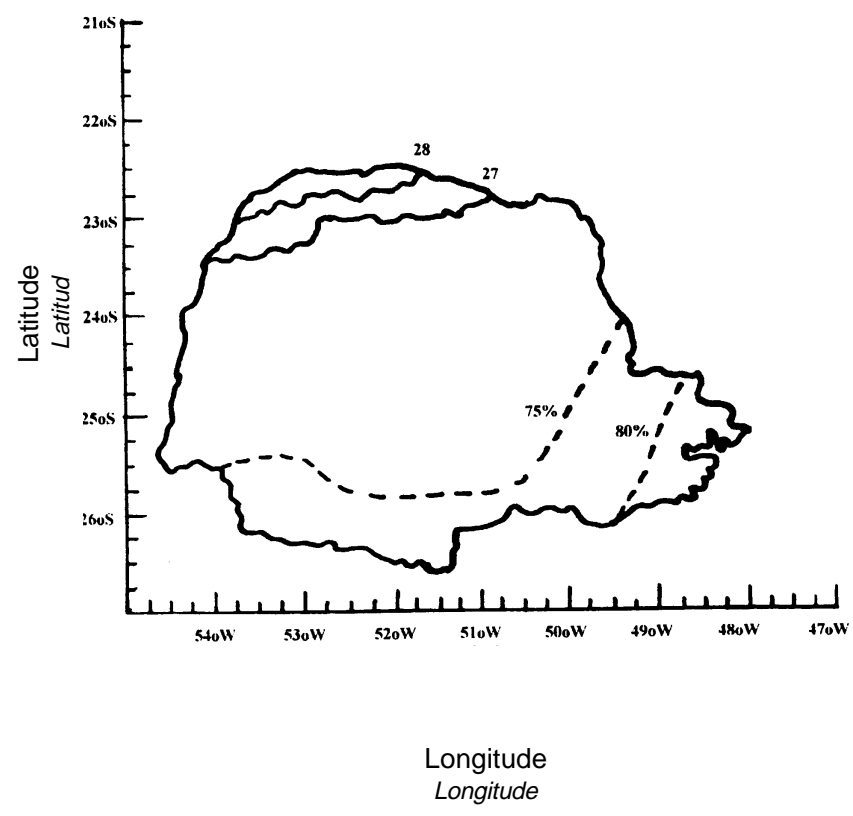

Figura 3 - Isolinhas de Conforto Térmico (linhas contínuas) e de Umidade Relativa do ar (\%) (linhas pontilhadas), no mês de julho, no Estado do Paraná.

Figura 3 - Isolines of Thermal Comfort (continuous lines) and Air Relative Humidity (\%) (stripped lines) for the month of July, in the State of Parana.

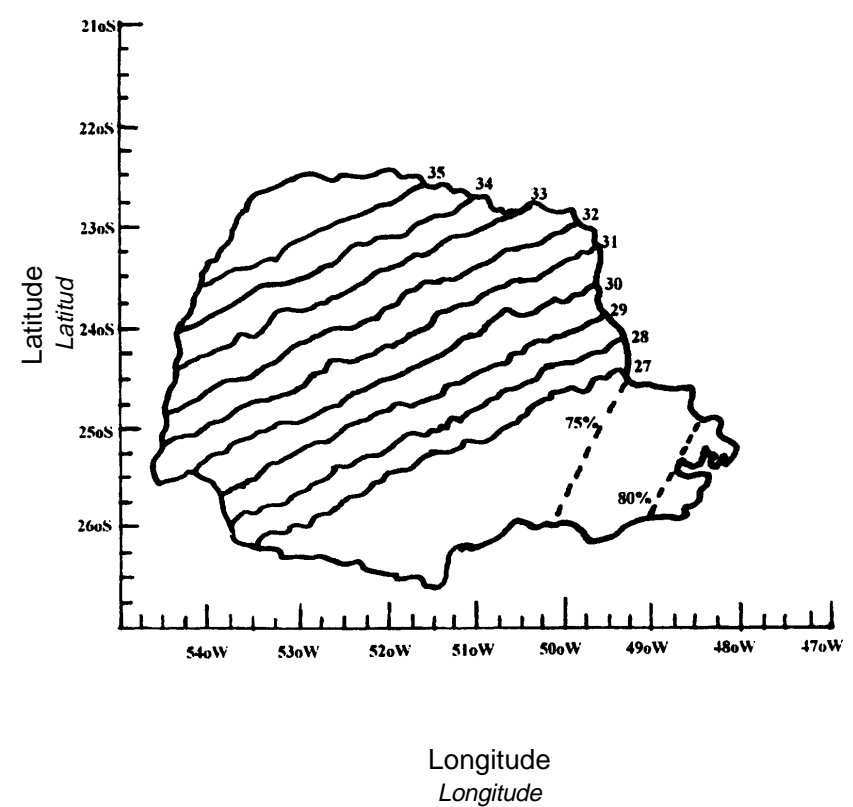

Figura 4 - Isolinhas de Conforto Térmico (linhas contínuas) e de Umidade Relativa do ar (\%) (linhas pontilhadas), no mês de outubro, no Estado do Paraná.

Figura 4 - Isolines of Thermal Comfort (continuous lines) and Air Relative Humidity (\%) (stripped lines) for the month of October, in the State of Parana.

\section{Resultados e Discussão}

Na Tabela 1, são apresentados os valores dos elementos climáticos (temperatura do ar, pressão de vapor, temperatura do globo negro, velocidade do vento e a carga térmica radiante), obtidos durante o período experimental.

A regressão do Índice de Conforto Térmico (ICT) sobre a temperatura retal (Tr) (Figura 5) mostrou efeito quadrático $(\mathrm{P}<0,05)$ para as três raças (Hampshire Down, Texel e Ile de France). Pelas equações quadráticas estimadas, os pontos de mínima para as três raças foram: Hampshire Down, ICT=24,3; Texel, 27,3 e Ile de France, 20,6, obtendo, respectivamente, para as três raças, temperatura retal de 39,$10 ; 39,05 ; \mathrm{e} 39,09^{\circ} \mathrm{C}$, atingindo 40,$40 ; 40,50$; e $40,28^{\circ} \mathrm{C}$, respectivamente, para ICT $=58$. As três raças aumentaram sua Tr já a partir destes índices, sendo que a raça Texel foi a que apresentou os menores valores absolutos até ICT $=46$; neste ponto, as três raças se equipararam; após este valor a raça Texel foi a que apresentou os maiores valores absolutos para Tr.

Com relação à frequência respiratória $(\mathrm{Fr})$ (Figura 6), os pontos de mínima obtidos pelas equa-

Tabela 1 - Valores máximos, mínimos e médios da temperatura do ar (Ta), pressão de vapor PV), temperatura do globo $(\mathrm{Tg})$, velocidade do vento $(\mathrm{Vv})$ e da carga térmica radiante (CTR), durante o experimento

Table 1 - Maximum, minimum and average values of the air temperature (Ta), vapor pressure (PV), globe temperature $(T g)$, wind speed $(V v)$ and of the radiant heat load (CTR)

\begin{tabular}{|c|c|c|c|}
\hline $\begin{array}{l}\text { Variável climática } \\
\text { Climatic variable }\end{array}$ & $\begin{array}{l}\text { Máxima } \\
\text { Maximum }\end{array}$ & $\begin{array}{l}\text { Mínima } \\
\text { Minimum }\end{array}$ & $\begin{array}{l}\text { Média } \\
\text { Average }\end{array}$ \\
\hline $\begin{array}{l}\text { Temperatura do ar } \\
\left(\mathrm{Ta}-{ }^{\circ} \mathrm{C}\right)\end{array}$ & 37,0 & 21,0 & 27,7 \\
\hline Air temperature & & & \\
\hline $\begin{array}{l}\text { Pressão de vapor } \\
\text { (PV - kPa) }\end{array}$ & 5,39 & 2,32 & 2,96 \\
\hline Vapor pressure & & & \\
\hline $\begin{array}{l}\text { Temperatura do globo } \\
\left(\mathrm{Tg}-{ }^{\circ} \mathrm{C}\right)\end{array}$ & 56,0 & 21,6 & 33,98 \\
\hline Globe temperature & & & \\
\hline $\begin{array}{l}\text { Velocidade do vento } \\
(\mathrm{V}-\mathrm{m} / \mathrm{s})\end{array}$ & 8,6 & 0,4 & 2,76 \\
\hline $\begin{array}{l}\text { Wind speed } \\
\text { Carga Térmica Radiante } \\
\left(\mathrm{CTR}-\mathrm{W} / \mathrm{m}^{2}\right) \\
\text { Radiant heat load }\end{array}$ & 1792,88 & 433,19 & 741,35 \\
\hline
\end{tabular}




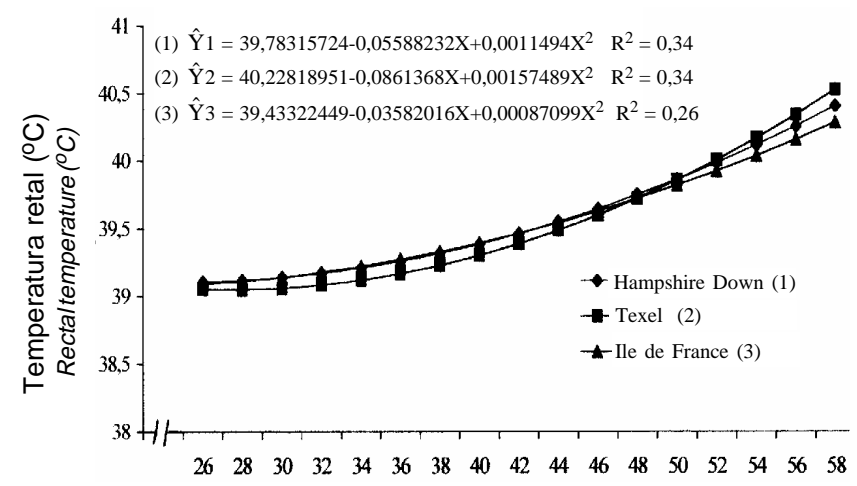

Índice de conforto térmico

Thermal confort index

Figura 5 - Efeito do Índice de Conforto Térmico sobre a temperatura retal $\left({ }^{\circ} \mathrm{C}\right)$, nos animais das raças Hampshire Down, Texel e lle de France.

Figure 5 - Effect of the Thermal Confort Index on the rectal temperature $\left({ }^{\circ} \mathrm{C}\right.$ ) of Hampshire Down, Texel and lle de France sheep.

ções quadráticas foram: ICT=27,6, 29,7 e 27,0, para as raças Hampshire Down, Texel e Ile de France, bem como os valores para a Fr de 89,63; 77,08; e 78,77 resp./min., respectivamente.

Para ICT $=26$, a Fr foi de 90,25; 81,18; e 79,02 resp./min. para as raças Hampshire Down, Texel e Ile de France, respectivamente. A raça Hampshire Down mostrou Fr em valor absoluto sempre superior ao das demais raças em todos os valores de ICT. A raça Texel apresentou menor Fr (77,08 resp./min.), para ICT $=29,7$, sendo que para ICT $=48$ atingiu valores semelhantes à Ile de France (179,63 resp./min.). A partir deste índice a Fr, passou a ser maior, atingindo valores absoluto de 288,66 resp./min. para ICT $=56$, porém inferior ao da raça Hampshire Down (289,01 resp./min.). Neste índice, a raça Ile de France foi a que apresentou o menor valor absoluto de $\mathrm{Fr}$ (275,72 resp./min.).

Embora a raça Texel tenha tido $\mathrm{Fr}$ e $\mathrm{Tr}$ em valores absoluto menores que as demais raças até ICT $=46$, nenhuma delas mostrou ser tolerante ao calor, visto que, mesmo elevando suas Fr, não foram capazes de manter constante a $\mathrm{Tr}$.

Este resultado pode estar relacionado ao fato de estas raças terem sido desenvolvidas para condições ambientais médias bem diferentes daquelas existentes nos ambientes estudados, que resultaram em esforços para a termorregulação.

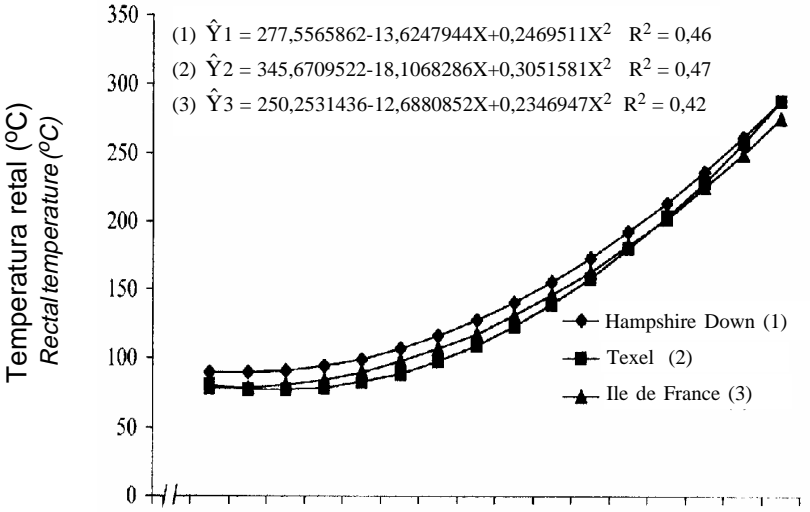

$\begin{array}{llllllllllllllll}26 & 28 & 30 & 32 & 34 & 36 & 38 & 40 & 42 & 44 & 46 & 48 & 50 & 52 & 54 & 56\end{array}$

Índice de conforto térmico

Thermal confort index

Figura 6 - Efeito do Índice de Conforto Térmico sobre a freqüência respiratória (resp/min.), nos animais das raças Hampshire Down, Texel e lle de France.

Figure 6 - Effect of the Thermal Confort Index on the respiratory rate (resp/min.) of Hampshire Down, Texel and lle de France sheep.

\section{Zoneamento bioclimático}

$\mathrm{Na}$ Figura 7 são apresentados os valores médios do índice de conforto térmico e da umidade do ar durante o ano e na Figura 8, o zoneamento bioclimático das raças estudadas, em relação a tais valores. Nota-se que o conjunto destes meses apresenta distribuição mais uniforme da umidade do ar e do ICT. Esta melhor uniformidade permite encontrar valores de Índices entre 30 e 35 para umidade do ar na faixa de 75 a 80\% (Figura 8), a qual tende a limitar a criação de ovinos especializados na produção de lã, mas favorece as raças de carne.

Combinando as isolinhas de ICT e da umidade atmosférica (Figura 8), tem-se então representada uma delimitação geográfica para as três raças de ovinos. Nesta figura, os limites foram estabelecidos pelas isolinhas do ICT médio durante o ano, havendo duas destas linhas, ICT $=30$ e ICT $=35$.

As três raças apresentaram respostas fisiológicas semelhantes, mostrando dificuldades fisiológicas para índices superiores a 30. Assim, uma extensa faixa ao longo do litoral do Estado do Paraná, entrando cerca de $200 \mathrm{~km}$ para o interior, até os limites das cidades de Castro, Telêmaco Borba, Laranjeiras do Sul e Pato Branco, permitiria a criação das três raças citadas, sem exigir dos animais grandes esforços no seu mecanismo termorregulador.

$\mathrm{O}$ zoneamento foi feito considerando-se estrita- 


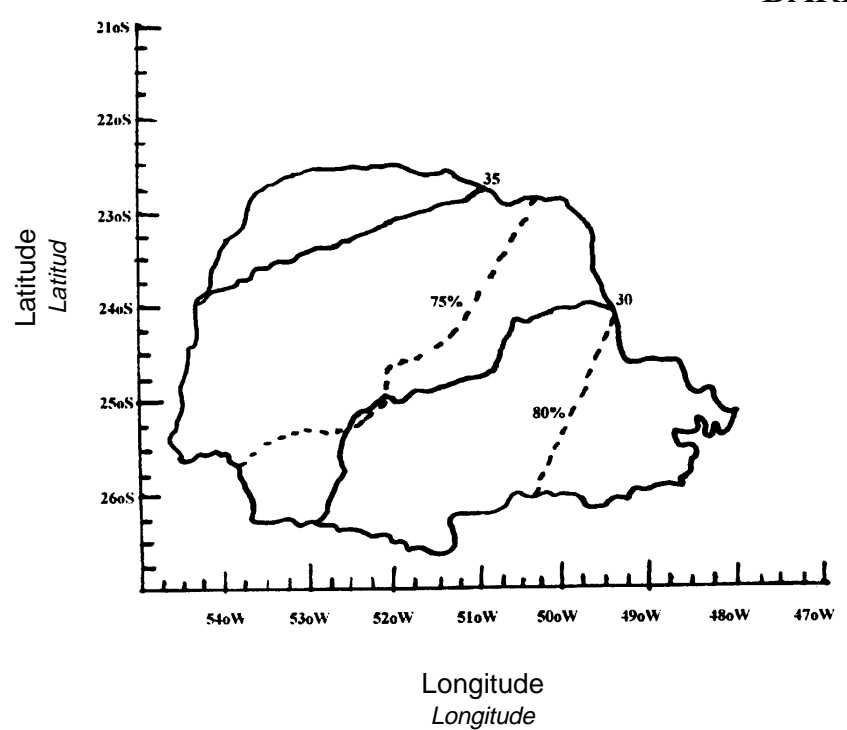

Figura 7 - Valores médios do Índice de Conforto Térmico (linhas contínuas) e da Umidade Relativa do ar (\%) (linhas pontilhadas), no Estado do Paraná.

Figure 7 - Average values of the Index fo Thermal Comfort (continuous lines) and Air Relative Humidity (\%) (stripped lines), in the State of Parana.

mente o conforto térmico dos animais, delimitando as zonas onde cada uma das três raças poderia ser criada sem grandes problemas. Porém, é preciso destacar que o microclima específico de alguns locais pode ser mais vantajoso ou mais adverso, apesar de se encontrar em determinada zona. As pastagens, por exemplo, são um fator condicionante importante e que devem ser consideradas. A zona costeira imediata do Estado, embora seja uma faixa bastante estreita, evidentemente não constitui ambiente adequado para quaisquer das raças ovinas consideradas, em vista de apresentar altas temperaturas e elevada umidade ao longo do ano.

Finalmente, o conhecimento dos efeitos do meio ambiente sobre os animais pode ajudar na adoção de alternativas corretivas adequadas. Por exemplo, onde a radiação solar é mais intensa, devem-se proporcionar sombra e abrigos. $\mathrm{O}$ efeito da sombra fornecida aos animais, nas horas mais quentes do dia, é um fator importante (AZAMEL et al., 1987; JOHNSON, 1991).

Avaliando o efeito do sol sobre parâmetros fisiológicos em ovelhas, SIQUEIRA et al. (1993) observaram diferenças na Tr e Fr, quando compararam animais à sombra e expostos ao sol, confirmando o fato de que o uso de sombra propicia conforto térmico satisfatório aos animais, não prejudicando seu desempenho. Segundo SILANIKOVE (1987), a provi-

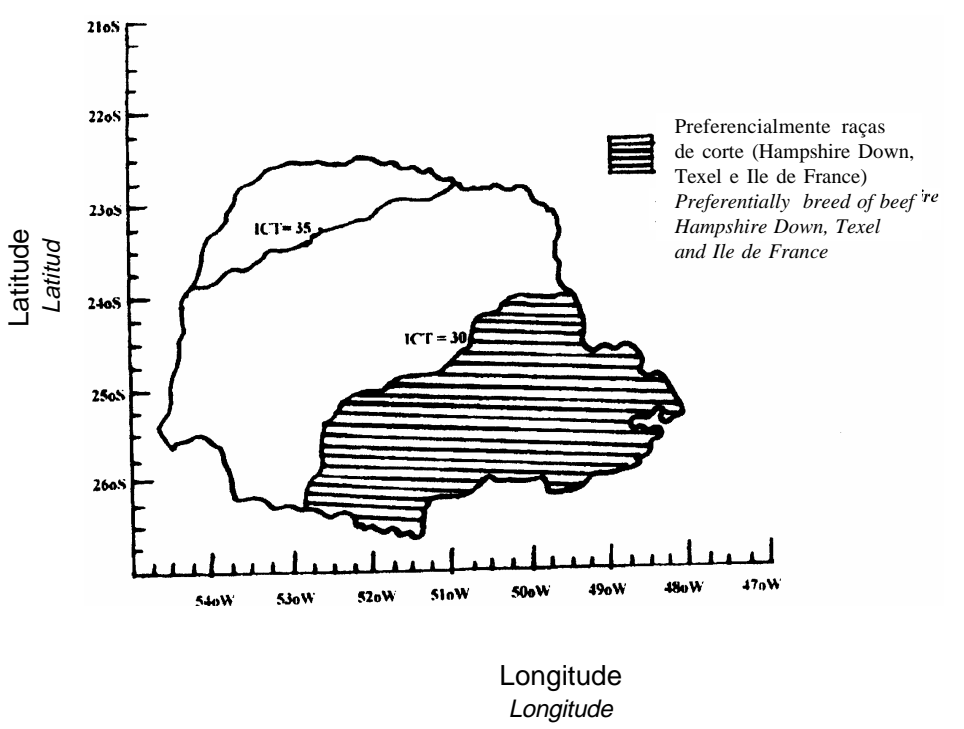

Figura 8 - Zoneamento bioclimático das raças Hampshire Down, Texel e lle de France, no Estado do Paraná.

Figura 8 - Bioclimatic zoning of Hampshire Down, Texel and lle de France sheep, in the State of Parana. são de sombra não altera a ingestão de alimento ou água por ovinos em ambientes quentes.

Possivelmente, a criação das raças estudadas, que requer temperatura amena e alta umidade, possa ser feita nas regiões com índice de ICT maior que 30, desde que se proporcione ainda sombra e/ou instalações adequadas.

\section{Conclusões}

Uma extensa faixa ao longo do litoral do Estado do Paraná, entrando cerca de $200 \mathrm{~km}$ para o interior, até os limites das cidades de Castro, Telêmaco Borba, Laranjeiras do Sul e Pato Branco, permite a criação das três raças, sem exigir grande esforço no seu mecanismo termorregulador.

\section{Referências Bibliográficas}

AZAMEL, A.A., YOUNIS, A.A., MOKHTAR, M.M. 1987. Effect of shading, shearing and breed type on heat tolerance and performance of lambs under semi-arid conditions. Ind. J. Anim Sci., 57(10):1132-1137.

BARBOSA, O.R., SILVA, R.G., SCOLAR, J. et al. 1995. Utilização de umíndice de conforto térmico no zoneamento bioclimático da ovinocultura. Rev. bras. zootec., 24(5):661-671.

BONA FILHO, A. OTTO, C., SAlGADO, A.A. et al. 1991. Cruzamento na pecuária ovina no Estado do Paraná. 
460 Rev. bras. zootec.

Rev. Setor Ciên. Agr., 11(1-2):293-296.

HAFEZ, E.S.E., BADRELDIN, A.L., SHARAFELDIN, M.A. 1956. Heat-tolerante studies of fat-tailed sheep in the tropics. J. Agric.Sci, 47(2):280-286.

HOPKINS, P.S., KNIGHTS, G.I., LE FEUVRE, A.S. 1978. Studies of the environmental physiology of tropical Merinos. Austr. J. Agric. Res., 29(1):61-71.

JOHNSON, K.G. 1991. Body temperature and respiratory rates of free-ranging Merino sheep in and out of shade during summer. Austr. J. Agric. Res., 42:1347-1357.

MONTY JR., D.E., KELLY, L.M., RICE, W.R. 1991. Aclimatization of St Croix, Karakul and Rambouillet sheep to intense and dry summer heat. Small Rum.Res., 4(4):379-392.

SHAFIE, M.M., SHARAFELDIN, M.A. 1965. Animal behaviour in the sub-tropics. I. Heat tolerance in relation to grazing behaviour in sheep. Netherl. J. Agric. Sci., 13(10):1-4.

SILANIKOVE, N. 1987. Impact of shelter in hot Mediterranean climate on feed intake, feed utilization and body fluid distribuition in sheep. Appetite., 9:207-215.

SILVA, R.G., BRASIL, D.F. 1986. Calibração de catatermômetro para avaliação de pequenos deslocamentos de ar. Ciências Zootec., 1(1):1-3.

SILVA, R.G. Equações para estimativas da carga térmica radiante através do globo de Vernon. In: WORKSHOP DE BIOCLIMATOLOGIA ANIMAL, 2, 1989, Jaboticabal. Proceedings... Jaboticabal.[s.n] 1989.
SIQUEIRA, E.R. Estudo da produção, correlações fenotípicas e repetibilidade das características da lã em cinco raças de ovinos no sitema intensivo de pastejo. Jaboticabal, SP, 1990. 121p. Tese ( Doutorado em Zootecnia) - Faculdade de Ciências Agrárias e Veterinárias, Universidade Estadual Paulista, 1990.

SIQUEIRA, E.R., FERNANDES, S., MARIA, G.A. 1993. Effecto de la lana y del sol sobre algunos parametros fisiologicos en ovejas de razas Merino Australiano, Corriedale, Romney Marsh e Ile de France. ITEA, 89A(2):124-131.

UNIVERSIDADE FEDERAL DE VIÇOSA-UFV. 1997. SAEG - Sistema de nálises estatísitcas e genéticas. Versão 7.1. Viçosa, MG. 150p. (Manual do usuário).

Recebido em: $17 / 06 / 00$

Aceito em: 18/12/00 